\title{
IMPERATIVES OF THE ECONOMIC INTEGRATION OF THE EURASIAN ECONOMIC UNION COUNTRIES
}

\author{
Olga G. Orlova \\ Volgograd State University, Volgograd, Russian Federation
}

\begin{abstract}
The development of integration of the Eurasian Economic Union (EAEU) countries is limited by the system of imperatives that includes challenges and threats to the interests and existence of the integration block and its members. The article identifies challenges to the development of the EAEU: liberal globalization, transition to the sixth technological order, global digital transformation, challenges associated with the emergence of new development centers and a new system of international redistribution of economic growth factors. It was established that external and internal challenges that do not receive well-timed and adequate answers are transformed into a system of threats. The paper provides a list of external threats to the Eurasian integration: threats, coming from western "partners" aimed at deterring and preventing integration processes in the EAEU, threats of a military nature, as well as threats of forming alternative integration projects. The author presents the analysis of internal threats: ethnic conflicts, changing foreign policies of the participating countries, conflicts of economic and political interests, problems of the financial and payment systems, limited mutual trade and investment relations, insufficient development of the transport infrastructure, the threat of "erosion" of a single economic and transit space of EAEU if the Unit is constructed on terms of "continental" integration. It is concluded that it is necessary to counteract the listed threats with measures of an economic, military-political or other nature.
\end{abstract}

Key words: Eurasian integration, Eurasian Economic Union, imperatives, challenges, threats.

Citation. Orlova O.G. Imperatives of the Economic Integration of the Eurasian Economic Union Countries. Journal of Volgograd State University. Economics, 2020, vol. 22, no. 1, pp. 183-191. (in Russian). DOI: https:// doi.org/10.15688/ek.jvolsu.2020.1.16

УДК 330.101.541:2-678

Дата поступления статьи: 09.12.2019

ББК 65.012.3-133

Дата принятия статьи: 09.01.2020

\section{ИМПЕРАТИВЫ ЭКОНОМИЧЕСКОЙ ИНТЕГРАЦИИ СТРАН ЕВРАЗИЙСКОГО ЭКОНОМИЧЕСКОГО СОЮЗА}

\author{
Ольга Геннадьевна Орлова \\ Волгоградский государственный университет, г. Волгоград, Российская Федерация
}

\begin{abstract}
Аннотация. Развитие интеграции стран Евразийского экономического союза (далее - ЕАЭС) ограничено системой императивов, включающей в себя вызовы и угрозы интересам и самому существованию интеграционного блока и его членов. В статье выявлены вызовы развитию ЕАЭС: либеральная глобализация; переход к шестому технологическому укладу; глобальная цифровая трансформация; вызовы, связанные с появлением новой системы международного перераспределения факторов экономического роста и новых центров развития. Установлено, что вызовы, не получающие своевременных и адекватных ответов, транс으 формируются в систему угроз. Перечислены внешние угрозы евразийской интеграции, среди которых: уг尺े розы со стороны западных «партнеров», направленные на сдерживание и предотвращение интеграционных п. процессов в ЕАЭС, угрозы военного характера, а также угрозы формирования альтернативных интеграционных проектов. Представлен анализ внутренних угроз, включающих: межнациональные конфликты, смену 气ิ๊ внешнеполитических курсов стран-участниц, конфликты экономических и политических интересов, проблео․ мы финансовой и платежной систем ЕАЭС, ограниченность взаимных торговых и инвестиционных отноше(2) ний, недостаточную развитость транспортной инфраструктуры, угрозу «эрозии» единого экономического и
\end{abstract}


транзитного пространства ЕАЭС при условии построения «континентальной» модели евразийской интеграции. Сделан вывод о необходимости противодействия перечисленным угрозам мерами экономического, военно-политического или иного характера.

Ключевые слова: евразийская интеграция, Евразийский экономический союз, императивы, вызовы, угрозы.

Цитирование. Орлова О. Г. Императивы экономической интеграции стран Евразийского экономического союза // Вестник Волгоградского государственного университета. Экономика. - 2020. - Т. 22, № 1. C. 183-191.-DOI: https://doi.org/10.15688/ek.jvolsu.2020.1.16

\section{Введение}

В 1991 г. одновременно с распадом Советского Союза были инициированы интеграционные процессы, которые с 1995 г. приобрели субрегиональный характер. 10 октября 2000 г. президенты Республики Беларусь, Республики Казахстан, Кыргызской Республики, Российской Федерации и Республики Таджикистан учредили Евразийское экономическое сообщество (далее - ЕврАзЭС). В январе 2010 г. начал функционировать Таможенный союз (далее - ТС) Республики Беларусь, Республики Казахстан и Российской Федерации, а в январе 2012 г. - Единое экономическое пространство (далее - ЕЭП) данных государств. В 2015 г. вступил в силу Договор о Евразийском экономическом союзе (далее - ЕАЭС) между государствами-членами ТС и ЕЭП, к которым присоединились Кыргызская Республика и Республика Армения.

Интеграционные процессы в ЕАЭС происходят в условиях глобальной трансформации мировой системы и международных отношений, встречают жесткое, а порой агрессивное, деструктивное противодействие со стороны конкурирующих центров силы, а также претерпевают проверку на прочность, преодолевая проблемы и противоречия внутри Союза. Все перечисленное следует отнести к системе императивов экономической интеграции в ЕАЭС, исследованию которых посвящена данная статья.

\section{Результаты и обсуждение}

Выявление императивов развития современных интеграционных процессов в ЕАЭС целесообразно начать с уточнения категории «императив». В данной статье императивы рассматриваются как экзогенные и эндогенные факторы, влияющие на траекторию раз- вития исследуемого интеграционного объединения. К императивам международной региональной интеграции отнесены вызовы и угрозы не только интересам государств-участников интеграционного процесса, но и существованию интегрированной хозяйственной системы такого формирования. Вызов развертыванию интеграции в ЕАЭС правомерно рассматривать как проблему общего характера, вызванную появлением новых факторов в мировом развитии и требующую адекватных ответных действий стран-членов для обеспечения конкурентоспособного, устойчивого и безопасного функционирования этого интеграционного блока [Иншакова, 2004, с. 188].

Глобальными вызовами странам постсоветского пространства являются:

1. «Либеральная глобализация», основанная на доминировании крупных транснациональных корпораций (далее - ТНК), эмиссии долларов ФРС США как мировых денег и ведущая к формированию глобального наднационального органа со своими наднациональными мегарегуляторами, средством достижения которой является реализация проектов с большими трансокеанскими зонами свободной торговли (трансатлантической и транстихоокеанской). Евразийская интеграция является адекватным ответом на этот вызов.

2. Смена технологических укладов и переход к шестому технологическому укладу, представляющему собой совокупность сопряженных производств, имеющих единый технический уровень и развивающихся синхронно, связанного главным образом с нанотехнологиями, информационными технологиями и гелио- и ядерной энергетикой, что будет способствовать разрушению существующей в России и Казахстане (ядре интеграционного блока) модели сырьевой экономики. Для избежания негативных последствий необходимы инвестиции в новые технологии, науку - в 
те области знаний, которые обеспечат опережающее или догоняющее развитие стран ЕАЭС [Глазьев].

3. Глобальная цифровая трансформация, предполагающая оцифровку экономики, создание новой модели экономического развития, меняющей мировой уклад и форму самоорганизации общества, сопровождающаяся усилением роли ТНК, влияние которых становится сильнее влияния многих государств. Этот процесс осуществляется путем формирования межотраслевых цифровых платформ, представляющих собой современную форму организации разделения труда по всему миру, связь оцифрованных отраслей с которой за счет максимизации добавочной стоимости позволяет резко повышать производительность труда, что является основным фактором экономического роста. Именно на него нацелена деятельность ЕАЭС.

Следует учитывать также, что создание цифровых площадок осуществляется ТНК, которые, сосредоточив управление мировым рынком в своих руках, смогут создавать вектор его глобального развития, управляя и воздействуя на бизнес стран ЕАЭС, вытесняя его с мирового и евразийского рынков. С помощью цифровых платформ ТНК также контролируют мировые финансовые потоки, изменяя вид и содержание финансового сектора экономики. Наконец, с помощью цифровых технологий ТНК создают такой механизм привлечения рабочей силы, который позволяет им использовать накопленные компетенции в различных интеллектуальных сферах в разных странах с минимальными издержками. Таким образом, цифровизация ТНК мировой экономики представляет серьезную угрозу основным приоритетам ЕАЭС, в частности, свободному движению товаров, услуг, капитала и рабочей силы. Адекватным ответом на этот вызов является формирование наднациональными органами ЕАЭС межотраслевых цифровых платформ в евразийском пространстве [Саркисян].

4. Вызовы, связанные с появлением новой системы международного перераспределения факторов экономического роста и новых центров развития, среди которых: сокращение географических и товарных рынков, ухудшение их конъюнктуры и ужесточение на них конкуренции; структурные изменения на мировом рынке труда; высокая потребность в развитии новейших технологий; необходимость формирования новых конкурентных преимуществ из-за исчерпания существующих (связанных с добычей и экспортом природных ресурсов) [«Основные направления ...]. Реализация стратегии «Основные направления экономического развития стран ЕАЭС до 2030 года» позволит нейтрализовать указанные вызовы.

Внешние и внутренние вызовы, не получающие своевременных и адекватных ответов, трансформируются в систему угроз. Под угрозой следует понимать «совокупность условий и факторов, препятствующих реализации национальных интересов стран-участниц интеграционного объединения, а также их групповых и общих интересов... Угрозу можно определить конкретно, с указанием ее источника... Ее возникновение требует незамедлительного противодействия экономического, военно-политического или иного характера, с помощью которых она может быть устранена» [Иншакова, 2004, с. 188-190].

Угрозой развитию ЕАЭС становятся действия по сдерживанию и предотвращению инициированных Россией интеграционных процессов в постсоветском пространстве со стороны стран «коллективного запада» [Клинтон]. Такие действия предпринимаются в соответствии со стратегическими директивами американского руководства, составной частью которых является план Вулфовица. Согласно последнему важнейшей задачей американской стратегии безопасности является недопущение в постсоветском пространстве создания, укрепления и развития союза, проводящего в Евразии самостоятельную политику, не соответствующую интересам США в данном регионе [Prevent the Reemergence ...; 1992 Draft Defense ...]. План Вулфовица и подобные ему документы представляют собой систему действий по интенсификации дезинтеграционных процессов и развала евразийского интеграционного блока через: содействие смене в нейтральных и дружественных России странах постсоветского пространства политических режимов на антироссийские, прозападные, глобалистские; сокращение и разрыв связей между РФ и бывшими союзными республиками; 
объединение соседних с Россией государств на основе русофобской политики в антироссийскую коалицию; сближение последних с ЕС и США, вступление в североатлантический альянс и размещение у себя военных объектов НАТО [Дугин].

Главным актором, осуществляющим реализацию американской глобалистской стратегии фрагментации постсоветского пространства, стал фонд Дж. Сороса, активно провоцировавший «цветные» революции в бывших союзных республиках, что впоследствии привело к созданию в них русофобских режимов и их присоединению к антироссийской (антиевразийской) коалиции.

В результате реализации вышеупомянутой «западной» стратегии по отношению к интеграции стран ЕАЭС возникли требующие особого внимания угрозы военного характеpa, среди которых:

1. Нахождение в непосредственной близости от России крупнейших воинских контингентов НАТО (участие в особой партнерской программе НАТО Армении, Казахстана, Молдовы, Украины, Грузии, Азербайджана, Сербии); наличие в перечисленных странах (а также в Узбекистане и Кыргызстане) биолабораторий США, которые проводят эксперименты с вирусами и осуществляют сбор разведданных.

2. Создание в Евросоюзе системы военного Шенгена, позволяющей оперативно и беспрепятственно передислоцировать вооруженные силы и военные грузы НАТО по территории ЕС до западных рубежей ЕАЭС.

3. Несогласованность военно-политических позиций стран-участниц ОДКБ [Новожеев].

Внешней угрозой для ЕАЭС также является реализация в постсоветском пространстве альтернативных интеграционных проектов, осуществляемых США, ЕС, КНР и Турцией и предназначенных стать новыми центрами притяжения для бывших союзных республик, провоцирующими ослабление, а в перспективе и разрыв связей внутри ЕАЭС. К проектам, «отвлекающим внимание» государств постсоветского пространства от ЕАЭС и делающим единую модель безопасности и интеграции этих стран труднодостижимой, относятся:

1. «Организация за демократию и экономическое развитие» - ГУАМ, созданная в
1997 г. при поддержке США и активизировавшая свою деятельность с 2015 г., в состав которой вошли Грузия, Украина, Азербайджан и Молдова. Деятельность организации нацелена на то, чтобы ослабить экономические и энергетические связи с Россией; перенаправить транзит нефти и газа из Азии в Европу через Кавказ в обход территории РФ; не допустить присутствия российских вооруженных сил на территории стран-участниц. В 1999 г. президенты стран ГУАМ подписали Вашингтонскую декларацию, в которой зафиксировали намерение интегрироваться в ЕС и НАТО. С 2017 г. государства-участницы работают над реализацией программы сотрудничества со странами Вышеградской четверки, Японией, США и Канадой, созданием общего координационного органа, а также над созданием зоны свободной торговли.

2. «Содружество демократического выбора» («сообщество демократий балто-черноморско-каспийского региона»), созданное при содействии ЕС и США в 2005 г., участниками которого являются Литва, Латвия, Эстония, Грузия, Молдова, Украина, Румыния, Словения, Северная Македония. Формально основателями организации выступали Грузия и Украина. Деятельность Содружества нацелена на: укрепление позиций на постсоветском пространстве; поддержку оппозиции в постсоветских государствах, ориентированных на интеграцию с Россией; включение в свой состав республик, переживших «цветные» революции; реализацию стремления к интеграции в ЕС в противовес России и интеграционным объединениям с еe участием; вступление в ОБСЕ и НАТО; участие в основных внешнеполитических программах США в регионе (все страны-члены СДВ являются приоритетными партнерами Соединенных Штатов).

3. Проект «Восточное партнерство», реализуемый ЕС с целью поэтапного включения в свой состав южнокавказских государств (Азербайджана, Армении, Грузии), а также государств западного пространства СНГ (Молдовы, Украины, Беларуси) путем постепенной отмены препятствий во взаимной торговле и включения норм европейского законодательства в правовую систему стран-участниц, имеет следствием диверген- 
цию их хозяйственных механизмов и внешнеэкономических комплексов с российскими. Данный проект, имея антироссийский характер, влечет серьезные риски для ЕАЭС, так как предполагает создание альтернативных российским энергетических проектов и транспортных коридоров, что создает очевидные угрозы и существенно снижает его энергетический и транзитный потенциалы [Хапилин, 2015, с. 22-30].

4. Проект «Большой Центральной Азии», продвигаемый США, который нацелен на отсечение от России стран Средней Азии и их интеграцию с Афганистаном, Пакистаном и государствами Южной Азии, а также их совместное сотрудничество с США и НАТО. Основными инструментами реализации данного проекта являются: энергетический проект CASA-1000 (Central Asia - South Asia), возобновленный проект ТРАСЕКА (Транспортный коридор Европа - Кавказ - Азия), а также встречи в формате «С $5+1 »($ стран Средней Азии и США).

5. Китайский проект «Шелкового пути», основанный на концепции новой межконтинентальной транспортной системы для перемещения грузов и пассажиров по суше из Китая в Европу. Проект предполагает создание нескольких маршрутов по территории постсоветских государств в обход России с участием Казахстана, Узбекистана, Туркменистана, Азербайджана, Грузии, Украины и стран Балтии, способствуя их сближению друг с другом и с Китаем. Только северный сухопутный маршрут частично пролегает по территории России.

6. Проект тюркской интеграции «Новый османизм», инициированный Турцией, который предполагает сотрудничество Турции, Азербайджана, Туркменистана, Казахстана и Кыргызстана (а в перспективе и Узбекистана) в гуманитарной, культурной и образовательной сферах, переходящее к более тесной политической и экономической консолидации; а также разработку и транспортировку нефти и газа, развитие транспортных коридоров.

Ко внутренним угрозам развитию интеграционных процессов в ЕАЭС следует отнести:

1. Тлеющие межнациональные конфликты в постсоветском пространстве (между
Украиной и Россией, Грузией и Россией, Арменией и Азербайджаном, Кыргызстаном и Узбекистаном), а также нерешенное противоречие водопользования в Центрально-Азиатском регионе из-за неравномерного распределения водных ресурсов.

2. Изменение внешнеполитических курсов стран ЕАЭС (кроме России), вызванное многовекторной политикой руководителей этих стран.

Так, в Армении после произошедшей в 2018 г. революции и смены власти заметно изменились внешнеполитические приоритеты. Важнейшими стратегическими партнерами были объявлены Турция и ЕC, тесное партнерство с которыми может существенно снизить значимость сближения со странами ЕАЭС. Политические лидеры Республики Беларусь также переориентировались на культурное и политическое сближение с ЕС, продолжая настаивать на получении экономических льгот от России. Все меньше места для интеграции с Россией оставляет и многовекторная политика Казахстана, направленная на сближение с Западом, Китаем и исламским миром. В этом же направлении движется и Кыргызстан, который в ожидании инвестиций из Китая проявляет все большую готовность к сближению с последним [Лепехин].

3. Угрозы экономического характера: олигархизация экономики; вывоз капитала; хранение активов евразийских государств в зарубежных банках и в зарубежных ценных бумагах; наличие задолженности стран ЕАЭС перед международными финансовыми институтами и ТНК; существенные убытки, возникающие в результате использования глобальными конкурентами режимов персональных, коллективных и других видов санкций (особенно по отношению к России); зависимость экономической элиты ряда евразийских государств от зарубежных стран. Так, высший экономический суд Казахстана, созданный на базе Международного финансового центра Астаны, возглавляет главный судья Англии и Уэльса лорд Гарри Вульф, там же работают еще несколько судей из Великобритании, при этом в основу правосудия на территории МФЦА заложено не евразийское, а английское право [Новожеев]. 
4. Несоответствие, а иногда и конфликт экономических интересов стран-участниц, подрывающие жизнеспособность ЕАЭС, вызванные: дифференциацией социально-экономического развития стран-участниц ЕАЭС; конкуренцией национальных налоговых режимов; сложностью определения страны происхождения технически несложных товаров и, как следствие, нелегальный ввоз на территорию ЕАЭС товаров из третьих стран, особенно через границу Беларуси и Казахстана; привлечением прямых иностранных инвестиций (особенно китайских) путем создания свободных экономических зон и производством на территории стран-участниц высококонкурентных (чаще китайских) товаров, представляющих угрозу вытеснения России с рынков этих стран, а также с роли лидера интеграционных процессов; начислением экспортных пошлин и введением нетарифных ограничений, обостряющим внутренние конфликты (например, между Россией и Беларусью); несогласованностью внешнеторговой политики по отношению к третьим странам, особенно после введения санкций против России и ее ответных антисанкционных мер [Ганеева, 2017, с. 168-177] и др.

5. Обострение финансовых проблем государств-членов Союза, среди которых: снижение поступлений из-за колебания цен на экспортные товары; жесткая монетарная политика и «дороговизна» кредитов для бизнеса в РФ; недостаточный объем денежной массы в обращении; рост заимствований за рубежом, влекущий рост внешней задолженности; недофинансирование реального сектора; увеличение дефицитов госбюджетов; снижение реальных темпов экономического роста и как следствие уязвимость экономического сотрудничества между странами-членами ЕАЭС [Ганеева, 2017, с. 168-177].

6. Отсутствие единой евразийской платежной системы, представляющее угрозу развитию экономических отношений между странами-членами ЕАЭС ввиду зависимости проведения взаимных расчетов от иностранных платежных систем Visa и MasterCard. И хотя для нейтрализации данной угрозы Евразийская экономическая комиссия (далее - ЕЭК) разрабатывает единую расчетную систему для стран ЕАЭС, которая способна интегрироваться с международными платежными си- стемами, позволяет использовать национальные валюты стран ЕАЭС в электронных взаиморасчетах и способствует созданию интегрированного валютного рынка, результаты деятельности ЕЭК в этом направлении пока недостаточны.

7. Сохранение экспортно-сырьевой модели развития России и Казахстана (доля сырья в экспорте Казахстана в 2018 г. составила $74 \%$ [Анализ состояния ...], а России 65,5 \% [Итоги внешней ...]), предопределяющее их ориентацию на рынки третьих стран и позиционирование себя не как торговых партнеров, а как конкурентов и на мировом, и на внутреннем рынке ЕАЭС, что ставит под угрозу углубление евразийской интеграции.

8. Незначительный удельный вес торговых и инвестиционных связей между такими парами стран, как Киргизия - Армения, Армения - Беларусь, Беларусь - Киргизия, Армения - Казахстан, в общей системе экономических связей ЕАЭС.

9. Недостаточная развитость транспортной инфраструктуры ЕАЭС (разрывы в транспортных коммуникациях, приводящие к транспортной изолированности отдельных регионов или государств, недостаточное количество мультимодальных транспортно-логистических центров, ограниченная пропускная способность пограничных переходов между сопредельными странами, недостаточное количество подвижного состава, несопряженность видов транспорта, дисбаланс транзитного грузопотока и др.).

10. Угроза «эрозии» единого экономического и транзитного пространства, а также промышленного комплекса ЕАЭС в случае построения «континентальной» модели евразийской интеграции на принципе открытого регионализма. Нейтрализация данной угрозы может быть осуществлена посредством ограничения потенциальных границ ЕАЭС государствами постсоветского пространства [Хапилин, 2015, с. 22-30].

Следует заметить, что в представленном исследовании перечислена лишь часть вызовов и угроз евразийской интеграции. Система императивов развития ЕАЭС гораздо шире и исследовать их целесообразно в «триединстве» с приоритетами и ориентирами интеграционной политики Союза. 


\section{Заключение}

В ходе исследования было установлено, что экономическая интеграция стран ЕАЭС ограничена системой императивов, к которым относят вызовы и угрозы интересам и самому существованию интеграционного блока и его членов.

К вызовам интеграции в постсоветском пространстве следует отнести либеральную глобализацию, сопровождающуюся ослаблением суверенных государств и усилением ТНК, а также переход к шестому технологическому укладу, одной из составляющих которого является глобальная цифровая трансформация. Евразийская интеграция является ответом на указанные вызовы, а также на вызовы, связанные с появлением новых центров развития и новой системы международного перераспределения факторов экономического роста.

Внешние и внутренние вызовы, не получающие своевременных и адекватных ответов, трансформируются в систему угроз. К внешним угрозам относят: угрозы со стороны западных «партнеров», направленные на сдерживание и предотвращение интеграционных процессов в ЕАЭС, угрозы военного характера, а также угрозы формирования в постсоветском пространстве альтернативных интеграционных проектов. Среди внутренних угроз выявлены: межнациональные конфликты, смена внешнеполитических курсов станучастниц, конфликты экономических и политических интересов, проблемы финансовой и платежной систем, ограниченность взаимных торговых и инвестиционных отношений, недостаточная развитость транспортной инфраструктуры, а также угроза «эрозии» единого экономического и транзитного пространства ЕАЭС при условии построения «континентальной» модели евразийской интеграции. Для устранения угроз развитию интеграционных процессов в ЕАЭС требуется незамедлительное противодействие экономического, военно-политического или иного характера.

\section{СПИСОК ЛИТЕРАТУРЫ}

Анализ состояния внешней торговли Казахстана 2018 года // Портал для казахстанских экспор- теров. - 2019. - Электрон. текстовые дан. Режим доступа: http://export.gov.kz/page/poregionam-kazakhstana (дата обращения: 13.11.2019). - Загл. с экрана.

Ганеева, М. В. Внутренние угрозы экономической безопасности Евразийского Экономического Союза / М. В. Ганеева // Вестник Российского университета дружбы народов. Серия: Экономика. -2017 . - Т. 25, № 2. - С. 168-177.

Глазьев, С. Ю. О мерах по обеспечению устойчивости российской экономики / С. Ю. Глазьев. 2016. - Электрон. текстовые дан. - Режим доступа: https://realnoevremya.ru/articles/42704 (дата обращения: 04.07.2019). - Загл. с экрана.

Дугин, А. Г. Международные организации, способные стать основой многополярного миропорядка в правовом поле / А. Г. Дугин. - 2016. Электрон. текстовые дан. - Режим доступа: https://www.geopolitica.ru/article/ mezhdunarodnye-organizacii-sposobnye-statosnovoy-mnogopolyarnogo-miroporyadka-vpravovom (дата обращения: 18.08.2019). - Загл. с экрана.

Иншакова, Е. И. Экономическая интеграция в СНГ: методология, стратегия, механизм : монография / Е. И. Иншакова. - Волгоград : Волгогр. науч. изд-во. $-2004 .-372$ c.

Итоги внешней торговли РФ в 2018 год// Официальный сайт министерства экономического развития РФ. - Электрон. текстовые дан. - Режим доступа: http://economy.gov.ru/wps/wcm/connect/ d75b65eb-17e2-4771 ItogiTorgovli2018.pdf/ (дата обращения: 13.11.2019). - Загл. с экрана.

Клинтон, Х. США не допустят воссоздания СССР под новыми названиями «Таможенный союз или Евразийский союз» / Х. Клинтон. - 2012. - Электрон. текстовые дан. - Режим доступа: http:// earth-chronicles.ru/news/2012-12-07-35636 (дата обращения: 15.12.2019). - Загл. с экрана.

Лепехин, В. А. Противоречивое единство стран Евразийского экономического союза / В. А. Лепехин. - 2019. - Электрон. текстовые дан. Режим доступа: http://i-eeu.ru/category/news/ protivorechivoe-edinstvo-stran-evrazijskogoekonomicheskogo-soyuza (дата обращения: 20.10.2019). - Загл. с экрана.

Новожеев, Р. Угрозы и вызовы евразийской интеграции в XXI веке / Р. Новожеев. - 2018. - Электрон. текстовые дан. - Режим доступа: https:/ /ruskline.ru/analitika/2018/03/03/ugrozy i vyzovy_evrazijskoj_integracii_v_xxi_veke (дата обращения: 01.07.2019). - Загл. с экрана.

«Основные направления экономического развития ЕАЭС до 2030 года». Решение Высшего Евразийского экономического совета от 16.10. 2015 г., № 28, раздел 3. - Электрон. тек- 
стовые дан. - Режим доступа: http:// www.eurasiancommission.org/ru/act/integr_ i_makroec/dep_makroec_pol/seminar/Documents /Решение\%20№28\%20ОНЭР.pdf(дата обращения: 05.04.2019). - Загл. с экрана.

Саркисян, Т. С. Цифровая трансформация экономики ЕАЭС: новые угрозы и источники роста. Консолидированная позиция бизнеса / Т. С. Саркисян. 2017. - Электрон. текстовые дан. - Режим доступа: http:/www.eurasiancommission.org/ru/nae/ news/Pages/10-02-2017-150407.aspx (дата обращения: 02.07.2019). - Загл. с экрана.

Хапилин, С. А. Обеспечение экономической безопасности государств Евразийского экономического союза в условиях конкуренции моделей интеграции / С. А. Хапилин // Национальные интересы: приоритеты и безопасность. - 2015. - № 33. - С. 22-30.

1992 Draft Defense Planning Guidance // Militarist Monitor. - Electronic text data. - Mode of access: http://www.rightweb.irc-online.org/profile/ 1992_Draft_Defense_Planning_G... (date of access: 08.11.2019). - Title from screen.

Prevent the Reemergence of a New Rival // National Security Archive. - Electronic text data. - Mode of access: http://www.gwu.edu/ nsarchiv/ nukevault/ebb245/index.htm (date of access: 08.11.2019). - Title from screen.

\section{REFERENCES}

Analiz sostoyaniya vneshney torgovli Kazakhstana 2018 goda [Analysis of the State of Foreign Trade of Kazakhstan in 2018]. Portal dlya kazakhstanskikh eksporterov [Portal for Kazakhstan Exporters], 2019. URL: http:// export.gov.kz/page/po-regionam-kazakhstana (accessed 13 November 2019).

Ganeeva M.V. Vnutrennie ugrozy ekonomicheskoy bezopasnosti Evraziyskogo Ekonomicheskogo Soyuza [Internal Threats to the Economic Security of the Eurasian Economic Union]. Vestnik Rossiyskogo universiteta druzhby narodov. Seriya: Ekonomika [RUDN Journal of Economics], 2017, vol. 25, no. 2, pp. 168-177.

Glazyev S.Yu. O merakh po obespecheniyu ustoychivosti rossiyskoy ekonomiki [On Measures to Ensure the Sustainability of Russian Economy], 2016 URL: https://realnoevremya.ru/ articles/42704 (accessed 4 July 2019).

Dugin A.G. Mezhdunarodnye organizatsii, sposobnye stat osnovoy mnogopolyarnogo miroporyadka v pravovom pole [International Organizations Capable of Becoming the Basis of a Multipolar World Order in the Legal Field], 2016. URL: https://www.geopolitica.ru/article/ mezhdunarodnye-organizacii-sposobnye-statosnovoy-mnogopolyarnogo-miroporyadka-vpravovom (accessed 18 August 2019).

Inshakova E.I. Ekonomicheskaya integratsiya $v S N G$ : metodologiya, strategiya, mekhanizm: monografiya [Economic Integration in the CIS: Methodology, Strategy, Mechanism. Monograph]. Volgograd, Volgogradskoe nauchnoe izd-vo, 2004. 372p.

Itogi vneshney torgovli RF v 2018 god [Results of Foreign Trade of the Russian Federation in 2018]. Ofitsialnyy sayt ministerstva ekonomicheskogo razvitiya $R F$ [Official Website of the Ministry of Economic Development of the Russian Federation], 2019. URL: http://economy.gov.ru/wps/wcm/connect/ d75b65eb-17e2-4771 ItogiTorgovli2018.pdf/ (accessed 13 November 2019).

Klinton Kh. Klinton: SShA ne dopustyat vossozdaniya SSSR pod novymi nazvaniyami «Tamozhennyy soyuz ili Evraziyskiy soyuz» [Clinton: USA Will not Allow the Reconstruction of the USSR Under the New Names "Customs Union or Eurasian Union"], 2012. URL: http://earthchronicles.ru/news/2012-12-07-35636 (accessed 15 December 2019).

Lepekhin V.A. Protivorechivoe edinstvo stran Evraziyskogo ekonomicheskogo soyuza [Contradictory Unity of the Countries of the Eurasian Economic Union], 2019. URL: http://ieeu.ru/category/news/protivorechivoeedinstvo-stran-evrazijskogo-ekonomicheskogosoyuza/ (accessed 20 October 2019).

Novozheev R. Ugrozy i vyzovy evraziyskoy integratsii $v X X I$ veke [Threats and Challenges to Eurasian Integration in the $21^{\text {st }}$ Century], 2018. URL: https://ruskline.ru/analitika/2018/03/03/ ugrozy_i_vyzovy_evrazijskoj_integracii_v_xxi_veke/ (accessed 1 July 2019).

«Osnovnye napravleniya ekonomicheskogo razvitiya EAES do 2030 goda». Reshenie Vysshego Evraziyskogo ekonomicheskogo soveta ot 16.10. 2015 g., № 28, razdel 3 ["Main Directions of Economic Development of the EAEU Until 2030". Decision of the Supreme Eurasian Economic Council of October 16, 2015, no. 28, Section 3]. URL: http://www.eurasiancommission.org/ru/act/ integr_i_makroec/dep_makroec_pol/seminar/ Documents/Reshenie\%20№28\%20ONJeR.pdf) (accessed 5 April 2019).

Sarkisyan T.S. Tsifrovaya transformatsiya ekonomiki EAES: novye ugrozy i istochniki rosta. Konsolidirovannaya pozitsiya biznesa [Digital Transformation of the EAEU Economy: New Threats and Sources of Growth. Consolidated 
О.Г. Орлова. Императивы экономической интеграции стран Евразийского экономического союза

Business Position], 2017. URL: http:// www.eurasiancommission.org/ru/nae/news/Pages/ 10-02-2017-150407.aspx (accessed 2 July 2019).

Khapilin S.A. Obespechenie ekonomicheskoy bezopasnosti gosudarstv Evraziyskogo ekonomicheskogo soyuza v usloviyakh konkurentsii modeley integratsii [Ensuring the Economic Security of the States of the Eurasian Economic Union in the Context of Competition of Integration Models]. Natsionalnye interesy: prioritety $i$ bezopasnost [National Interests: Priorities and Security], 2015, no. 33, pp. 22-30. 1992 Draft Defense Planning Guidance. Militarist Monitor. URL: http://www.rightweb.irc-online.org/profile/ 1992_Draft_Defense_Planning_G (accessed 8 November 2019).

Prevent the Reemergence of a New Rival. National Security Archive. URL: http:/www.gwu.edu/ $\sim$ nsarchiv/nukevault/ebb245/index.htm (accessed 8 November 2019).

\section{Information About the Author}

Olga G. Orlova, Candidate for a Degree, Department of Economic Theory, World and Regional Economics, Volgograd State University, Prosp. Universitetsky, 100, 400062 Volgograd, Russian Federation, volgosros@yandex.ru, https://orcid.org/0000-0001-8910-3732

\section{Информация об авторе}

Ольга Геннадьевна Орлова, соискатель кафедры экономической теории, мировой и региональной экономики, Волгоградский государственный университет, просп. Университетский, 100, 400062 г. Волгоград, Российская Федерация, volgosros@yandex.ru, https://orcid.org/0000-0001-8910-3732 